\title{
Saline intake in gerbils (Meriones unguiculatus)
}

\author{
RODERICK WONG \\ University of British Columbia, Vancouver, Canada
}

\begin{abstract}
Experiment 1 assessed the $\mathrm{NaCl}$ preference-aversion function of gerbils on the two-bottle test. The results indicated that gerbils do not show the strong preference for $0.9 \% \mathrm{NaCl}$ that rats do. There was also no significant difference between the gerbils' intake of $0.9 \%$ and $2.0 \% \mathrm{NaCl}$. However, there was a significant decrease in the gerbils' saline consumption when the solution was $4.0 \%$ by weight. Experiments 2 and 3 demonstrated that the interposition of a single bottle of hypertonic saline prior to the two-bottle test with isotonic saline and water can decrease the gerbils' preference for isotonic saline relative to a control group. This effect depended upon the tonicity of the interposed solution. Although rats show a marked reduction in saline preference following exposure to a single bottle of $2.0 \% \mathrm{NaCl}$ for $24 \mathrm{~h}$, gerbils do not react similarly. However, when the interposed solution is $4.0 \% \mathrm{NaCl}$, gerbils show a subsequent reduction in isotonic saline intake. These results suggest parametric differences between the variables affecting fluid regulation of mesophytic and xerophytic adapted animals which reflect species differences in renal handling of osmotic loads.
\end{abstract}

The Mongolian gerbil (Meriones unguiculatus) is a remarkable rodent whose ability to conserve water reflects the animal's physiological adaptation to natural selection pressures of a dry, xerophytic, desert environment. This rodent can manufacture all its water requirements from its solid food diet and can utilize higher concentrations of $\mathrm{NaCl}$ solution than can rats (Winkelman \& Getz, 1962). Because most of our knowledge about fluid ingestion in rodents has been derived from the rat, it is possible that our models about the regulation of consumption are appropriate only to animals adapted to a mesophytic habitat. We must come to grips with speciesspecific components of the regulatory mechanism as well as general principles of such regulation. The gerbil was evolved from a xerophytic niche and undoubtedly, its mode of adaptation to water requirements is very different from that of the rat. Thus we would expect some interesting differences in the way the gerbil responds to various experimental conditions.

Until recently, there have been few well-controlled experimental studies on the water and saline consumption of gerbils. Grimsley (1973) sought to determine the gerbil's intake of salt solutions of varying concentration. Numerous studies have shown that rats show greater preference for isotonic saline than any other concentration of the solution or of water (see the review by Young, 1966). In attempting to derive the $\mathrm{NaCl}$ preference-aversion function among gerbils, Grimsley used the single-stimulus method

This research was supported by a grant from the National Research Council of Canada, 67-0247. I thank Beverly Clark for her help in gathering and analyzing the data. developed in the classic study on rats by Weiner and Stellar (1951). This method involves the presentation of only one solution at a time, and thus choice behavior is not directly assessed with this method. Grimsley's gerbils were water-deprived for $19 \mathrm{~h}$ before the 1-h tests, and one of five test solutions of varying concentration was used each day. The results indicated that the maximum intake of $\mathrm{NaCl}$ occurred at the $\mathbf{0 . 9 \%}$ (isotonic) level. Concentrations of saline above and below this level produced much lower intakes.

In view of the discussion of ecological and physiological differences between rats and gerbils, it is surprising that the preference-aversion function of gerbils was found to be so similar to the curve for rats. Although Grimsley (1973) argued that the concentration maximally preferred through the singlestimulus method correlates well with preference measures, it is nonetheless paramount that the gerbil's preference should be studied in a direct choice situation. I believe that a distinction must be drawn between preference and intake. Young (1966) had pointed out that the single-stimulus method is not a true preference method because it excludes the possibility of choice.

There is another aspect of Grimsley's (1973) procedure that makes an interpretation of his results problematic. Throughout his experiment, the gerbils were fed a salt-deficient diet and were water-deprived $19 \mathrm{~h}$ before each test session. It should be noted that all of the studies indicating maximum preference for $0.9 \% \mathrm{NaCl}$ solution among rats involved animals tested under normal, nondeprived conditions. For this reason, it is impossible to compare Grimsley's findings among gerbils with preference for isotonic saline among rats. If anything, sodium-deprived 
rats prefer hypertonic saline over solutions of lower tonicity. Thus, I feel that data on the preferenceaversion function in gerbils should be gathered among animals fed a normal balanced diet.

In a recent study comparing the consumatory behavior of voles and gerbils, Laughlin, Donovick, and Burright (1975) tested the animals' intake of solutions including $0.9 \%$ and $3.2 \% \mathrm{NaCl}$. With the single-stimulus method, the nondeprived gerbils' consumption of both isotonic and hypertonic saline solution was about equivalent to that of water. When tested with the double-stimulus method, the gerbils ingested more water than either isotonic or hypertonic saline. Certainly these results are different from those obtained by Grimsley (1973) and are challenging. It is partly for this reason that the present experiment was conducted.

\section{EXPERIMENT 1}

\section{Method}

The subjects were 15 male gerbils (Meriones unguiculatus) ranging in weight from 50 to $70 \mathrm{~g}$ at the beginning of the experiment. They were housed in plastic mouse cages (Carworth) measuring $12 \times 17 \times 27 \mathrm{~cm}$ with Sanicell bedding and Purina Lab Chow on the floor.

I tested the two-bottle preferences of gerbils by placing a bottle of water and one of saline through the wire cage lids. The left-right position of the bottles was alternated from day to day, and the daily intake from each bottle was recorded at the same time $(0900 \mathrm{~h})$. The animals were first tested for 8 days with a bottle of water and one of $2.0 \% \mathrm{NaCl}$ solution. Then they were given water only for the subsequent 8 days before being tested with a bottle of water and one of $0.9 \% \mathrm{NaCl}$. Following another 8 days where water was the only source of fluid, the gerbils were then given a choice between water and $4.0 \% \mathrm{NaCl}$ for another 8 days.

\section{Results and Discussion}

Data from the two-bottle test were first analyzed in terms of a preference score consisting of (saline intake/saline + water intake) $\times 100$. This score minimizes the error due to individual variation in total fluid consumption within and between subjects. The saline preference of the gerbils over the 8 test days for each $\mathrm{NaCl}$ concentration is shown in Figure 1. An examination of the data indicated that, unlike rats, gerbils do not show a strong preference for $0.9 \% \mathrm{NaCl}$ solution. In contrast to the rats' tendency to show a saline preference of about $70 \%$ (Davenport, 1973; Wong, 1977), the gerbils showed about $53 \%$ preference for isotonic saline. When the gerbils were tested with $2.0 \% \mathrm{NaCl}$ solution, they showed about $46 \%$ saline preference. There was no significant difference between the gerbils' intake of $0.9 \%$ and $2.0 \% \mathrm{NaCl}(\mathrm{p}>.05)$.

When the gerbils were tested with $4.0 \% \mathrm{NaCl}$, their saline preference dropped to $31 \%$. The t-test of the difference scores indicated that the gerbils significantly reduced their saline intake when the solution was $4.0 \%$. Comparisons between their

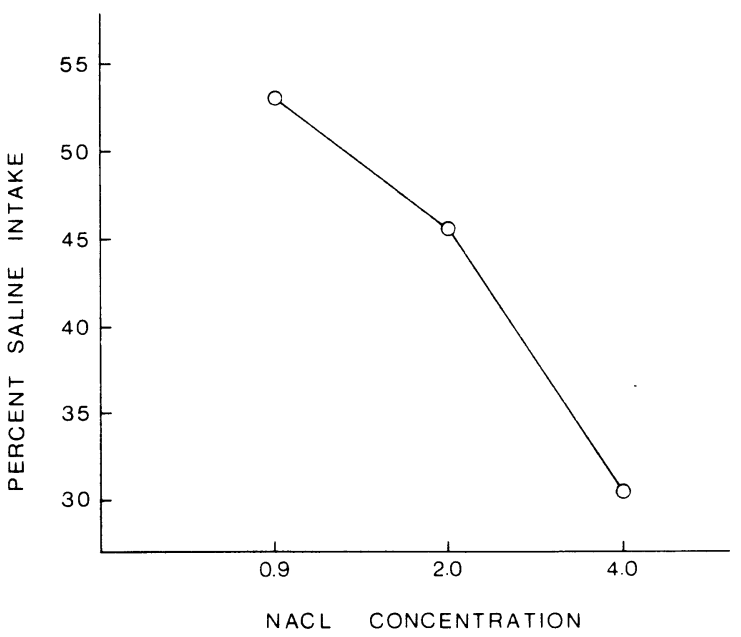

Figure 1. Percent saline intake of gerbils on the two-bottle test.

intakes of $0.9 \%$ and $4.0 \% \mathrm{NaCl}(\mathrm{t}=4.36, \mathrm{p}<.001)$ and of $2.0 \%$ and $4.0 \% \mathrm{NaCl}(\mathrm{t}=6.10, \mathrm{p}<.001)$ demonstrated this point.

The data on the gerbils' absolute intake of water and saline were also analyzed. Their mean intake of $0.9 \% \mathrm{NaCl}$ during the 8 test days was $7.5 \mathrm{ml}$, in contrast to their intake of $5.1 \mathrm{ml}$ of water. When tested with $2.0 \% \mathrm{NaCl}$ and water, the gerbils drank $8.6 \mathrm{ml}$ of saline and $8.9 \mathrm{ml}$ of water. However, when offered a choice between $4.0 \% \mathrm{NaCl}$ and water, the animals' mean intake of saline was $4.2 \mathrm{ml}$ and that of water was $8.5 \mathrm{ml}$. The matched-group t test was used to compare the animals' intake of water and $0.9 \%$, $2.0 \%$, and $4.0 \% \mathrm{NaCl}$. The only significant comparison was that between $4.0 \% \mathrm{NaCl}$ and water $(\mathrm{t}=2.90$, $\mathrm{p}<.05)$. These findings corroborate the outcome of the analysis of the saline preference scores.

The finding that gerbils showed about a chancelevel preference for $2.0 \% \mathrm{NaCl}$ is particularly interesting. Observations on the low (8\%) preference of rats for $2.0 \% \mathrm{NaCl}$ indicate that they find this solution aversive (Wong \& Kraintz, 1977). The fact that gerbils show about $46 \%$ preference for $2.0 \% \mathrm{NaCl}$ suggests that this solution does not have the same negative effects on their intake as it does with rats.

Although gerbils do not prefer $4.0 \% \mathrm{NaCl}$ to water, they nevertheless show a higher preference for this solution than do rats for $2.0 \% \mathrm{NaCl}$. I did not test the rats' preference scores for $4.0 \% \mathrm{NaCl}$, but it is likely that they would not drink more of it than of a $2.0 \% \mathrm{NaCl}$ solution. I also did not test the gerbils' preference for hypotonic saline solution. Because their preference for isotonic saline was at a chance level, it is unlikely that they would drink less saline relative to water as the tonicity decreases and the substances of the two bottles becomes more similar. 


\section{EXPERIMENT 2}

Although rats offered a choice between water and isotonic saline solution prefer saline, they show a decrease in this preference following the interposition of a single bottle of either isotonic or hypertonic saline prior to the two-bottle retest (Devenport, 1973). Recently, I have shown that this effect occurs only among rats that had been reared on water prior to the test sessions (Wong, 1977). Rats that had been reared on isotonic saline from weaning until testing time do not exhibit the Devenport effect. These results were interpreted in terms of Devenport's hypothesis that the ability of saline to expand the intracellular and extracellular space is poor compared with that of water. Thus these are mildly aversive consequences from the ingestion of saline. I had predicted that rats adapted to isotonic saline would not experience the degree of aversive postingestional effects from saline consumption that normally reared rats do, and the results appear to support this prediction.

Up to the time of the present experiment, there has not been any published evidence on the existence of the Devenport effect with species other than rats. In order to assess the generality of the Devenport phenomenon as well as to test the validity of his proposed mechanism underlying this effect, I tested gerbils using the Devenport paradigm. The results of this experiment would be particularly interesting because of the gerbils' unique ability to utilize hypertonic saline. Although the results of Experiment 1 suggest that gerbils do not necessarily prefer isotonic saline over water, it is nevertheless possible that the interposition of hypertonic saline could decrease their level of saline preference to below chance or $50 \%$.

The present experiment consisted of exposing a new group of gerbils to water and isotonic saline for 3 days before half of the group was given exclusive access to $2.0 \% \mathrm{NaCl}$ and the other half access to water for $24 \mathrm{~h}$. The aim of this experiment as to determine whether the interposition of $2.0 \% \mathrm{NaCl}$ would decrease the gerbils' subsequent preference for isotonic saline in the two-bottle test relative to those receiving the interposition of water.

\section{Method}

The subjects were 16 male gerbils (Meriones unguiculatus) that were housed in $12 \times 17 \times 2 \mathrm{~cm}$ plastic mouse cages. The floor was covered with Sanicell bedding and Purina Lab Chow was avilable ad lib. The gerbils were tested with the two-bottle procedure in a manner similar to that of Experiment 1 . This procedure was followed for 3 days.

After their baseline level of saline and water intake was assessed, the gerbils were split into two groups. One group received a bottle of $2.0 \% \mathrm{NaCl}$ solution for $24 \mathrm{~h}$ and the other group received water during this period. Following this period of single-bottle exposure, the gerbils were tested for another 5 days in the twobottle situation. All two-bottle measures were obtained during a 24-h continuous access period.

\section{Results and Discussion}

Data from the two-bottle test were first analyzed in terms of the saline preference ratio used in Experiment 1 . The results indicated no significant difference between the experimental and control groups during the critical two-bottle test sessions $(p<.05)$. The group receiving the interposition of $2.0 \% \mathrm{NaCl}$ for $24 \mathrm{~h}$ showed a preference of $50 \%$ for isotonic saline during the two-bottle test, while the group receiving the interposition of water showed $52 \%$ preference for isotonic saline.

The effects of the interposition of a single bottle of $2.0 \% \mathrm{NaCl}$ on the gerbils' absolute intake of $0.9 \% \mathrm{NaCl}$ in the two-bottle test was also assessed. The mean saline intake of the experimental group was $8.1 \mathrm{ml}$, while that of the control group was $8.4 \mathrm{ml}$. These results are consistent with those derived from the saline preference analysis.

It is apparent that the interposition of $2.0 \% \mathrm{NaCl}$ did not decrease the gerbils' subsequent preference for $0.9 \% \mathrm{NaCl}$ during the two-bottle test. In contrast, Devenport's (1973) rats showed a-dramatic shift in saline preference as a result of this experimental procedure. This interexperimental difference is due in part to the fact that gerbils do not find the ingestion of $2.0 \% \mathrm{NaCl}$ solution as aversive as rats do. This finding suggests that the hypertonicity of the interposed solution per se is not the controlling mechanism underlying the Devenport effect. In Devenport's experiments, the effect was evident when either isotonic or $2.0 \%$ saline was interposted between the baseline and test sessions.

On the basis of the results of the present experiment, I feel that the Devenport effect is manifested only when the interposed solution is of a concentration that an animal finds aversive (i.e., accepts at a level lower than that of isotonic saline). The data of Experiment 1 indicate that $4.0 \% \mathrm{NaCl}$ is relatively aversive to gerbils and that the Devenport effect may be observed if I were to use a solution of this tonicity during the interposition phase of the experiment.

\section{EXPERIMENT 3}

\section{Method}

The subjects were 16 male gerbils (Meriones unguiculatus) that were housed and reared under the same conditions of those in Experiments 1 and 2. These animals were about 6 months old and had not been used in any previous experiments. They were assessed for 3 days in the two-bottle situation for their baseline intake of $0.9 \% \mathrm{NaCl}$ and water. Then eight gerbils were assigned to the experimental condition where they received a single bottle of $4.0 \% \mathrm{NaCl}$ for $24 \mathrm{~h}$. The other eight gerbils were assigned to the control condition, where they received a single bottle of water for $24 \mathrm{~h}$. Following this period of single-bottle exposure, the gerbils' intake of isotonic saline and of water in the twobottle situation was assessed for another 5 days.

\section{Results and Discussion}

An analysis of the saline preference scores of the gerbils indicated no significant difference between 
the experimental and control animals during the 3-day baseline period ( $p>.05$ ). However, following the 24-h interposition of either $4.0 \%$ saline or water, there was a significant difference between the groups, $\mathrm{F}(1,14)=5.56, \mathrm{p}<.05$. These data are plotted in Figure 2, and it can clearly be seen that the experimental animals showed a lower saline preference than the controls during the initial sessions. Multiple comparisons between the groups indicated that the suppression of saline intake among the experimental animals occurred during the first 2 test days $(p<.05)$. No differences were obtained during the subsequent test sessions. It can be seen that by the fifth test session, the saline preference of the experimental animals had recovered to the level that the control animals maintained throughout the session. An analysis of the absolute saline intake of gerbils in the experimental and control conditions revealed results similar to those obtained from the saline preference scores.

The results of the present experiment appear to support the hypothesis that the Devenport effect can be induced in gerbils if the interpolated solution is sufficiently concentrated so that it is below the animal's acceptance level. Although Devenport was able to induce the suppression of saline intake in rats with the interposition of isotonic or hypertonic $(2.0 \%)$ saline, I was not able to produce this effect in gerbils unless I used a more hypertonic $(4.0 \%)$ saline solution. Despite differences in the rat and the gerbil's baseline isotonic saline preference and the tonicity of the interposed solution, there appear to be parallel processes underlying the effect with these species. In the present experiment, the suppression effect was evident for only 2 days after the interposition of hypertonic saline. After two sessions, the experimental animals showed a gradual recovery to



Figure 2. Percent saline intake of gerbils on the two-bottle test with water and $0.9 \% \mathrm{NaCl}$ following the interposition of $4.8 \% \mathrm{NaCl}\left(\mathrm{O}_{-} \mathrm{O}\right)$ or water $(\mathrm{O}--\mathrm{O})$ for $24 \mathrm{~h}$. the baseline saline preference. This phenomenon also was observed with rats by Wong (1977).

\section{GENERAL DISCUSSION}

It is clear that there are a number of unique features of the gerbil's reactions to saline solution. Gerbils do not show a greater preference for isotonic saline than for any other concentration of the solution or of water. In contrast, comparable two-bottle comparisons with rats indicate that $0.9 \% \mathrm{NaCl}$ is preferred over water as well as $2.0 \% \mathrm{NaCl}$ (Young, 1966). However, when gerbils are tested with a highly hypertonic solution such as $4.0 \% \mathrm{NaCl}$, they show a decreased tendency to ingest such a solution. This behavioral finding is interesting because of the fact that the renal concentrating capacity of the $M$. unguiculatus probably exceeds the $600-700 \mathrm{mEq} \mathrm{Na}$ per liter found in $4.0 \% \mathrm{NaCl}$ solution. Detailed data on the renal concentrating capacity of $M$. unguiculatus has not been documented, but such information is available for the related genus, Gerbillus. Burns (1956) found than when fed salted barley, gerbils from North Africa produced urine that was $1300 \mathrm{mEq} \mathrm{Na}$ per liter (equivalent to about 7.6\% $\mathrm{NaCl}$ ). The present results indicate that although the renal system of $M$. unguiculatus can process $4.0 \%$ $\mathrm{NaCl}$, these animals will not ingest much of it if water is also available. Behaviorally speaking, the gerbils found $4.0 \% \mathrm{NaCl}$ relatively aversive but not the $2.0 \%$ and $0.9 \% \mathrm{NaCl}$ solutions.

The results of Experiments 2 and 3 are consistent with those from Almli and Weiss' (1975) series of experiments on the reactions of rats, gerbils and guinea pigs to various dipsogenic challenges. They found that these animals differed quantitatively rather than qualitatively in their responses to cellular stimuli for thirst. The rats' drinking following water deprivation and subcutaneous $\mathrm{NaCl}$ injections is more closely attuned to osmolality change than is the cue for gerbils and guinea pigs. These experimenters had also shown that the differential responses to osmotic stimuli were due to species differences in renal handling of osmotic loads. These differences, in turn, are related to renal functional capacity that has evolved to suit the species to its natural habitat. Our results suggest that, although the parameters are different, a model about the regulation of fluid ingestion of mesophytic adapted animals has some validity for the analysis of fluid consumption of xerophilous animals.

\section{REFERENCES}

Almli, C. R., \& Weiss, C. S. Behavioral and physiological responses to dipsogens: A comparative analysis. Physiology and Behavior, 1975, 14, 633-641. 
Burns, T. W. Endocrine factors in the water metabolism of the desert mammal, G. gerbillus. Endocrinology, 1956, 58. 243-254.

Devenport, L. D. Aversion to a palatable saline solution in rats: Interactions of physiology and experience. Journal of Comparative and Physiological Psychology, 1973, 83, 98-105.

Grimsley, D. L. $\mathrm{NaCl}$ preference in the gerbil. Physiological Psychology, 1973, 1, 93-94.

Laughlin, M. E., Donovick, P. J., \& Burright, R. G. Consummatory behavior in meadow voles (Microtus pennsylvanicus) and Mongolian gerbils (Meriones unguiculatus). Physiology and Behavior, 1975, 15, 185-189.

Weiner, I. H., \& Stellar, E. Salt preference of the rat determined by a single-stimulus method. Journal of Comparative and Physiological Psychology, 1951, 44, 394-401.

Winkelman, J. R., \& GeTz, L. L. Water balance in the Mongolian gerbil. Journal of Mammology, 1962, 43, 150-154.

Wong, R. Saline intake as a function of prior drinking experience. Behavioral Biology, 1977, in press.

Wong, R., \& Kraintz, L. Desalivation and saline ingestion in rats. Behavioral Biology, 1977, 19, 130-134.

Young, P. T. Hedonic organization and regulation of behavior. Psychological Review, 1966, 73, 59-86.

(Received for publication December 20, 1976; revision accepted February 4, 1977.) 